\title{
Insights from a joint analysis of Indian and Chinese monsoon rainfall data
}

\author{
M. Zhou ${ }^{1}$, F. Tian ${ }^{1}$, U. Lall ${ }^{2}$, and H. Hu ${ }^{1}$ \\ ${ }^{1}$ Department of Hydraulic Engineering, State Key Laboratory of Hydroscience and Engineering, Tsinghua University, \\ Beijing 100084, China \\ ${ }^{2}$ Department of Earth and Environmental Engineering, Columbia University, MC 4711 New York, NY 10027, USA \\ Received: 15 March 2011 - Published in Hydrol. Earth Syst. Sci. Discuss.: 31 March 2011 \\ Revised: 24 August 2011 - Accepted: 24 August 2011 - Published: 29 August 2011
}

\begin{abstract}
Monsoon rainfall is of great importance for agricultural production in both China and India. Understanding the features of the Indian and Chinese monsoon rainfall and its long term predictability is a challenge for research. In this paper Principal Component Analysis (PCA) method was adopted to analyze Indian monsoon and Chinese monsoon separately as well as jointly during the period 1951 to 2003 . The common structure of Indian monsoon and Chinese monsoon rainfall data was explored, and its correlation with large scale climate indices and thus the possibility of prediction were analyzed. The joint PCA results gives a clearer correlation map between Chinese monsoon rainfall and Indian monsoon rainfall. The common rainfall structure presents a significant teleconnection to Sea Surface Temperature anomaly (SSTa), moisture transport and other climate indices. Specifically, our result shows that Northern China would garner less rainfall when whole Indian rainfall is below normal, and with cold SSTa over the Indonesia region more rainfall would be distributed over India and Southern China. The result also shows that SSTa in the previous winter months could be a good indicator for the summer monsoon rainfall in China.
\end{abstract}

\section{Introduction}

Chinese monsoon and Indian monsoon are important for agricultural production and economy in China and India (Parthasarathy et al., 1988; Webster et al., 1998; Abrol and Gadgil, 1999). The two monsoons both belong to Asian monsoon and are primarily influenced by Indian Ocean and West Pacific Ocean. There are studies showing that they are

Correspondence to: F. Tian

(tianfq@tsinghua.edu.cn) somehow correlated. Kripalani and Singh (1993) argue that summer monsoon rainfall over Northern China is highly correlated with that over India, and the subtropical ridge over the Indian region is an important predictor for both regions. Other studies suggest a spatial teleconnection between them as monsoon rainfall over Northern China is in phase with that over India (Chang et al., 2000; Kripalani and Kulkarni, 2001), and Zhang et al. (2007) show that both East Asian monsoon and Indian summer monsoon have strong influences on China, especially in the Yangtze River basin. Also, it is widely believed that annual variations of Indian monsoon and Chinese monsoon are both teleconnected to tropical Sea Surface Temperature (SST), which plays an important role in the large scale climate system. Considering that both Indian monsoon and Chinese monsoon are related to El Nino-Southern Oscillation (ENSO), a previous study (Hu et al., 2005) shows that the ENSO-related phase of Indian monsoon has a significant positive correlation with rainfall variations in Northern China, while the ENSO-unrelated phase has a significant negative correlation with rainfall variations in Southwestern China. Yang and Lau (2004) also show that there is an upward trend of precipitation over Southeastern China while a downward trend over Northern China during their monsoon seasons from 1951 to 1998, and the underlying reasons of these trends are linked to an ENSO-like mode of SST. Moreover, Huang (1994) suggests that the precipitation in the center part of Eastern China is primarily linked to SST variations over the western tropical Pacific warm pool and the Indian Ocean. Also, there are some other studies focusing on the decadal and interdecadal variations of precipitation. For example, Chan and Zhou (2005) show that the interdecadal change of monsoon rainfall over China region is affected by the interactions between Pacific Decadal Oscillation (PDO) and ENSO.

Published by Copernicus Publications on behalf of the European Geosciences Union. 


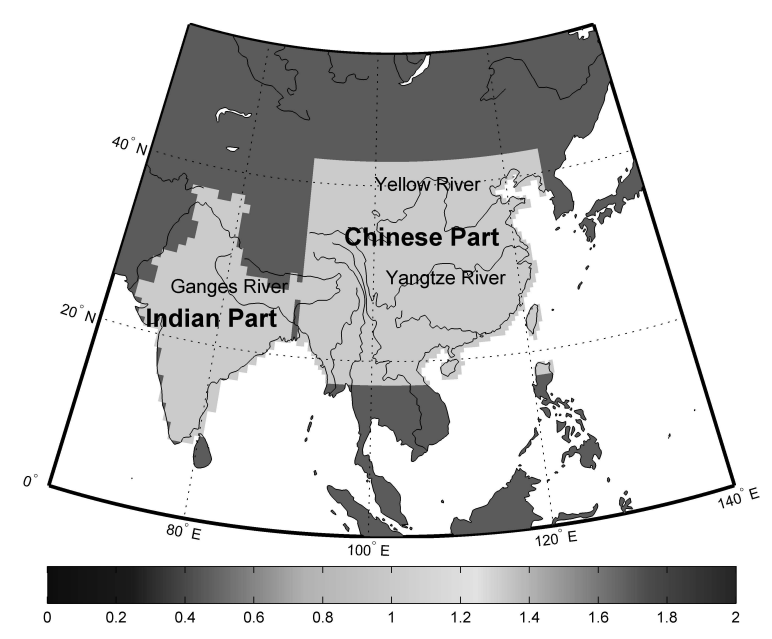

Fig. 1. The study area and major rivers.

It can be, therefore, concluded that Indian monsoon and Chinese monsoon are correlated in some way, and they are similarly influenced by some common climate drivers (like ENSO, SST, Subtropical ridge, etc. at annual scale) although the ways of influencing are different. Encouraged by these existing results, we consider that Indian monsoon and Chinese monsoon belong to a larger monsoon structure. The primary goal of this study is to figure out the common climate factors driving both monsoon structures at the annual scale, and the ways how these factors interplay in the mechanism of a larger monsoon structure. Principal Component Analysis (PCA) method is used to obtain the primary patterns of Chinese and Indian monsoon rainfall separately as well as jointly, and then the correlation analysis is performed between the derived principal components and climate indices like Sea Surface Temperature Anomalies and moisture transport with the purpose to explore the driving factors.

The remainder of this paper is organized as follows. In Sect. 2 we describe the sources of data used in this study. Following this, in Sect. 3 we first perform PCA on monsoon rainfall data of China and India separately and also the correlation analysis between them, and then we perform PCA again on the principal components of rainfall data of both India and China, and correlation analysis is also performed again to investigate the climate factors influencing monsoon rainfalls in the two regions. Finally we discuss our results in Sect. 4 together with the conclusions.

\section{Data}

The gridded rainfall data of China and India was collected from the World Climate Research Programme/Global Climate Observing System (WCRP/GCOS) Global Precipitation Climatology Centre (http://www.wcrp-climate. org/, http://www.wmo.int/pages/prog/gcos/index.php,http:// gpcc.dwd.de/), and the recording period is from the year of 1951 to 2003. The spatial resolution of collected rainfall data for Indian part and Chinese part is different. For the Indian part, the grid resolution is 1.0 by 1.0 degree and we chose to include the entire India (totally 357 grids), while for the Chinese part the resolution is 0.5 by 0.5 degree and we chose the area within $90^{\circ} \mathrm{E}-125^{\circ} \mathrm{E}, 17^{\circ} \mathrm{N}-43^{\circ} \mathrm{N}$ (totally 3024 grids), as shown in Fig. 1. To be noted, the latter area includes most part of China and also a small part of northern area of Southeast Asia (part of Myanmar, Thailand, Laos and Vietnam), which can represent the characteristics of Chinese monsoon and is, therefore, called Chinese part just for convenience. The Indian monsoon season is from June to September. In Chinese part, the monsoon season varies from region to region, i.e., it begins earlier in Southeastern China while later in Northern China. On average, it lasts for four months from June to September. In this study, we chose the monsoon season of China and India included the four months of June, July, August and September (shortly as JJAS). We acknowledge that the variability in monsoon timing and duration is critically important and the corresponding climate driving mechanisms is worthy of intense investigation, which is, however, beyond the scope of this paper and left for future research.

\section{Analysis and results}

\subsection{Principal component analysis of Indian monsoon and Chinese monsoon separately}

In this subsection we studied the correlations between monsoon rainfall patterns in India and China. First we performed the principal component analysis on Indian and Chinese yearly monsoon rainfall data individually. The results show that the first principal component (PC1) of India takes $20 \%$ of all and the second principal component (PC2) takes $10 \%$. For Chinese part, the PC1 takes $11 \%$ of all and PC2 takes $8 \%$. India PC1 and China PC1 have a negative correlation -0.5 , and India PC2 and China PC1 also have a negative correlation -0.4 . China PC2 has low correlation with India PCs. These suggest that Indian monsoon and Chinese monsoon have some patterns in common.

The spatial correlation patterns of India PCs and China PCs were further investigated, and the results are shown in Fig. 2. As indicated by Fig. 2c, India PC1 presents a high positive correlation with the rainfall in the middle part of India and the area around $40^{\circ} \mathrm{N} 110^{\circ} \mathrm{E}$ of China. This result confirms the existing conclusion that summer monsoon rainfall over India is in phase with the monsoon rainfall in the area around $40^{\circ} \mathrm{N} 110^{\circ} \mathrm{E}$ of China (Kripalani and Singh, 1993; Kripalani and Kulkarni, 2001). Also, India PC1 has a high negative correlation with rainfall in Southwestern China. On the contrary, China PC1 has an approximately opposite pattern compared to India PC1. The China PC1 
Table 1. Correlation coefficients between China/India rainfall PCs and monsoon indices (IMI \& WNPMI).

\begin{tabular}{lrrrrrr}
\hline Correlation & India PC1 & India PC2 & China PC1 & China PC2 & Joint PC1 & Joint PC2 \\
\hline IMI & 0.83 & 0.04 & -0.35 & -0.42 & -0.73 & -0.19 \\
WNPMI & 0.21 & -0.65 & -0.14 & 0.28 & 0.08 & 0.58 \\
\hline
\end{tabular}

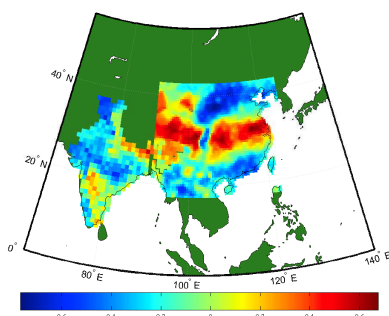

(a)

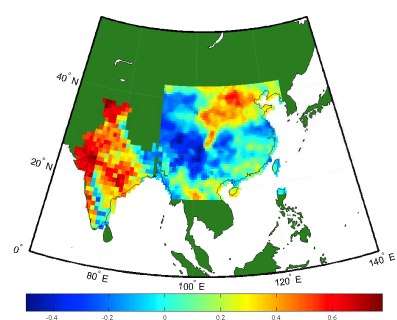

(c)

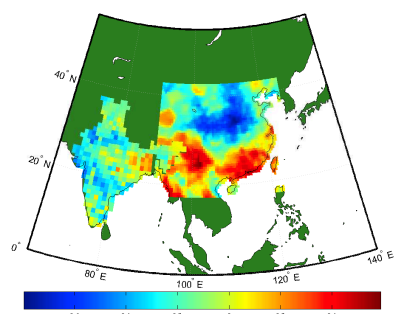

(b)

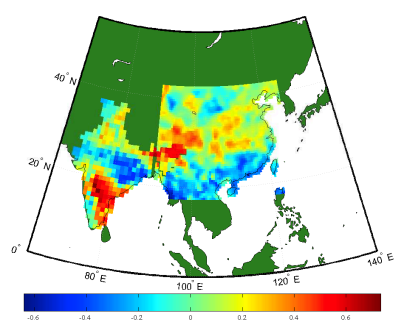

(d)
Fig. 2. Correlation maps between rainfall PCs and rainfall field of China and India. (a) China PC1 vs. rainfall field of China and India; (b) China PC2 vs. rainfall field of China and India; (c) India PC1 vs. rainfall field of China and India; (d) India PC2 vs. rainfall field of China and India.

has a high positive correlation with the rainfall in the middle eastern part of China (downstream of Yangtze River) while a high negative correlation with that in the northern part of India and northern part of China around $40^{\circ} \mathrm{N} 110^{\circ} \mathrm{E}$. It should be highlighted that both maps have similar dipole patterns in the middle part of India and middle eastern part of China (downstream of Yangtze River basin). We also list the corresponding results in Fig. 2b and d for China PC2 and India PC2 respectively. The similar phenomena could be found in PC2 figures compared to PC1 figures, which shows that India PCs have some common patterns with China PCs besides their own patterns.

Additionally, the correlation coefficients between China/India PCs and monsoon indices (Wang, et al., 2001), i.e., Indian Monsoon Index (IMI) and West-North Pacific Monsoon Index (WNPMI), were calculated, which are listed in Table 1. As we can see from Table 1, India PC1 is significantly correlated to IMI and India PC2 is highly correlated to WNPMI, which agrees with the previous study (Wang et al., 2001). Both China PC1 and PC2 are correlated to IMI, and the correlation coefficient of China PC1 is slightly higher than that of China PC2. China PC2 is also correlated to WNPMI, while China PC1 is not significantly correlated to WNPMI. To be noted, here and throughout this paper we take significant level for correlations is $99 \%$.

As the rainfall PCs we obtained present main trends of rainfall in the study areas, the correlation patterns between PCs in India and China suggest common factors affecting rainfall processes. The correlation analysis between PCs in both areas and IMI/WNPMI further reveals that Indian monsoon and West-North Pacific monsoon are two of these common factors. These possible common factors will be studied in more details using joint-PCA in Sect. 3.2.

\subsection{Joint principal component analysis of Indian monsoon and Chinese monsoon}

Since the length of time series is far less than the number of stations for our rainfall data, the ability of PCA to minimize noise is weakened. Furthermore, as the PCs of India and the PCs of China is well correlated, to get these common features (and to reduce noise), the joint PCA was performed with the following steps: first, we chose the first two leading PCs of India and China we got in Sect. 3.1; then we performed PCA again on the 4 PCs (India PC1, India PC2, China PC1, China PC2) and obtained 4 Joint PCs. Among them, the first and second principal component (joint PC1 and PC2) occupies $42 \%$ and $38 \%$ of the total weight respectively. We calculated correlation coefficients between the four individual PCs and four joint $\mathrm{PCs}$, and the results show that joint $\mathrm{PC} 1$ is highly related to China PC1 and India PC1, and joint PC2 is highly related to China PC2 and India PC2.

We studied the special patterns of joint PC1 and PC2 by looking at the correlation map between joint PCs and monsoon rainfall in the study area (Fig. 3). It is clear that the joint PC1 has high positive correlation with the rainfall in Middle China (mostly Yangtze River basin) and Southern India, and has high negative correlation with the rainfall in Northeastern China, part of Southern China, Northern India and Middle India (Fig. 3a). Over China, the pattern is uniform along east-west direction but varies from north to south, and can be divided into three regions along that direction. This variability may be caused by an early or late shift of subtropical jet (Kuang and Zhang, 2005) going from south to north of Tibet Plateau. It is almost opposite for joint PC2 (Fig. 3b), which has high positive correlation with Southern China and 


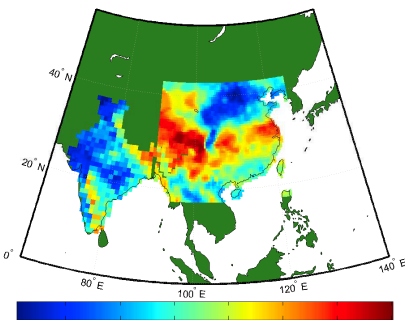

(a)

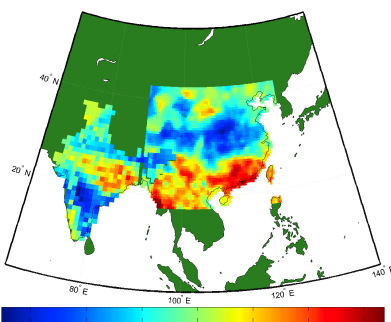

(b)
Fig. 3. Correlation maps between Joint PCs and rainfall field of China and India. (a) Joint PC1 vs. rainfall field of China and India; (b) Joint PC2 vs. rainfall field of China and India.

Middle India, and negative correlation with Middle China (mostly Yangtze River basin) and Southern India. From this figure, we can see that the pattern of joint PC2 is closely related to mid-east subtropical jet veered towards India, Indochina Peninsula and West Pacific Ocean. Joint PC2 loading of rainfall variability over India is more or less a dipole of rainfall over Ganges River basin: north cyclone route from Bay of Bangal (BoB) to Northern India and the relatively south route of the cyclones from BoB. The variability of Northern India is coherent with that over Indochina Peninsula and Southern China, probably with a common cause favoring cyclone activities.

Again, we compared these joint PCs with monsoon indices (see also Table 1). Joint PC1 is highly correlated to IMI, while joint PC2 is highly correlated to WNPMI. From the previous analysis, joint PC1 mostly comes from Middle China (mainly in Yangtze River basin) and South India, it keeps the feature of India PC1, i.e., the high correlation with IMI. Joint PC2 partly comes from China PC2, and is highly correlated to WNPMI, while China PC2 is not well correlated to WNPMI. This is because the second PCA derived a common character from China PCs and India PCs, which may or may not be present in the first PCA on Chinese monsoon and Indian monsoon alone.

In Sects. 3.1 and 3.2 the primary analysis method we use is PCA. As we know, the raw precipitation dataset used in this paper is huge, and the data is affected by some large scale climate factors that we are interested in, as well as other minor local factors. Those major climate factors determine the main trends in the raw data. PCA is capable of extracting the main trends from the raw data, and separating it from other minor fluctuations. Therefore it is a powerful method for our purpose. Besides PCA, some other methods can also be used for similar purposes such as independent component analysis (ICA) method and maximum value unfolding (MVU) method. ICA is a family of analyzing methods based on varied assumptions of statistical characteristics of the components in the raw data, while PCA uses a relatively simple assumption. Without any a priori knowledge of the climate factors we are looking for, PCA makes a good starting

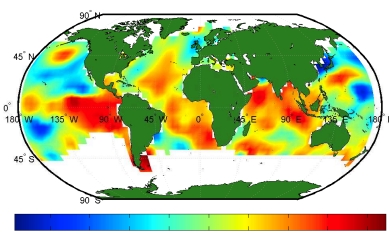

(a)

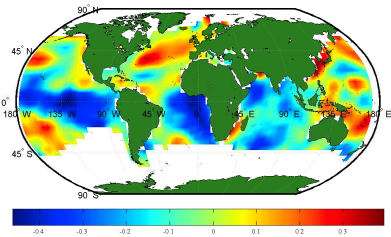

(c)

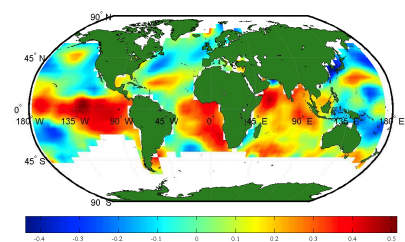

(e)

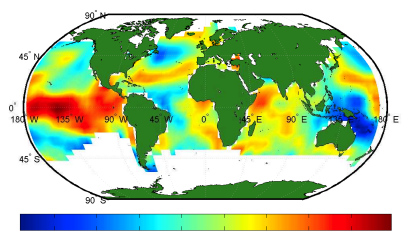

(b)

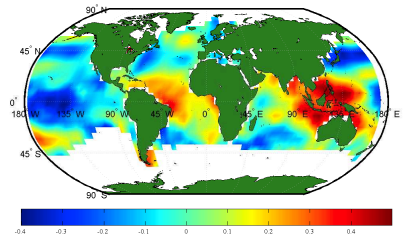

(d)

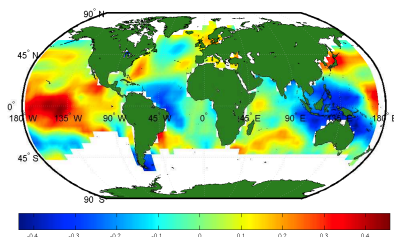

(f)
Fig. 4. Correlation maps between SSTa in the monsoon summer season (JJAS) and PCs. (a) China PC1 vs. SSTa; (b) China PC2 vs. SSTa; (c) India PC1 vs. SSTa; (d) India PC2 vs. SSTa; (e) Joint PC1 vs. SSTa; (f) Joint PC2 vs. SSTa.

point for our study. Comparing to MVU, a nonlinear analyzing method, PCA has the weakness of being linear and cannot fully represent the nonlinear nature in climate processes. However, it is also more stable against noises in the data because of its linearity, and it is an acceptable approximation for our purposes.

\subsection{Correlation with Sea Surface Temperature anomaly (SSTa) and other climate indices}

The Fig. 4 shows the correlation maps between SSTa in the monsoon summer season (JJAS) and China PCs, India PCs as well as joint PCs, which indicates that China PCs have positive correlations while India PCs have negative correlations with SSTa. The figures also show the significant influences of the ENSO on all PCs. Moreover, the Fig. 4d shows that India PC2 is influenced by Indian Ocean Dipole, which is in a different case for China PCs. The Fig. 4e and $f$ show the correlations between SSTa and the leading modes of joint PCs (i.e., joint PC1 and PC2). The results indicate that the joint PCs present clearer correlation pattern with SSTa than China and India PCs alone. The correlation coefficient between joint PC1 and SSTa within ENSO area is around 0.4-0.5, which is higher than the correlation coefficients (around 0.3-0.4) between China PCs or India PCs separately. The correlation coefficients between joint PC2 and SSTa are similar to those between India PC2 and SSTa, but higher than those between 


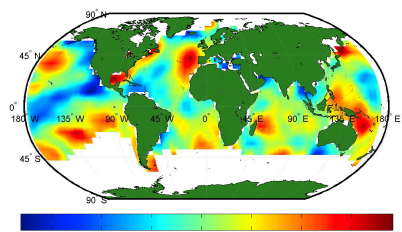

(a)

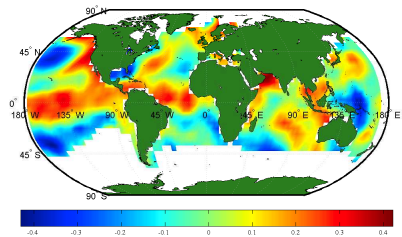

(c)

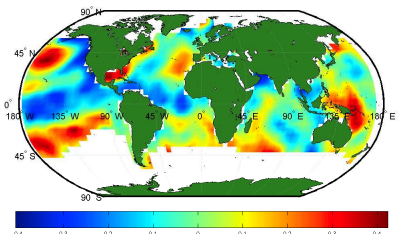

(e)

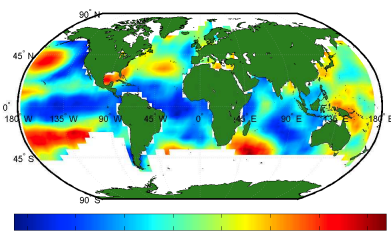

(b)

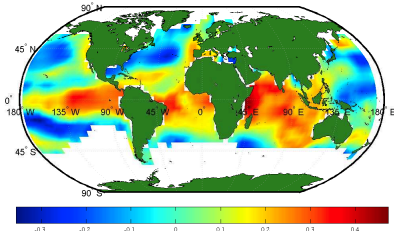

(d)

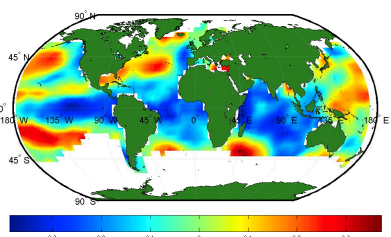

(f)
Fig. 5. Correlation maps between SSTa in the previous winter season (DJF) and PCs. (a) China PC1 vs. SSTa; (b) China PC2 vs. SSTa; (c) India PC1 vs. SSTa; (d) India PC2 vs. SSTa; (e) Joint PC1 vs. SSTa; (f) Joint PC2 vs. SSTa.

China PC2 and SSTa. Joint PC1 shows a significant positive correlation with SSTa in the months of JJAS within Pacific Ocean around $90^{\circ} \mathrm{W}-135^{\circ} \mathrm{W}, 10^{\circ} \mathrm{N}-10^{\circ} \mathrm{S}$, which is mainly Nino3 area. Joint PC2 shows a significant positive correlation within Pacific Ocean around $135^{\circ} \mathrm{E}-180^{\circ} \mathrm{E}, 10^{\circ} \mathrm{N}-$ $10^{\circ} \mathrm{S}$, which is mainly Nino4 area. Joint PC2 shows a significant negative correlation with Indonesian Sea.

Also presented here are the correlation maps (Fig. 5) between SSTa in the previous winter months (December, January and February, DJF) and PCs (India PCs, China PCs and joint PCs). Contrary to the correlation pattern between PCs and summer SSTa, joint PC1 shows a negative correlation with SSTa (DJF) around Nino 4 area, and joint PC2 shows a negative correlation with SSTa (DJF) around Nino 3 area. The correlation of summer SSTa with the joint PC1 (Fig. 4e) shows warm anomaly over the whole tropical belt except West Pacific Ocean, especially over Indian Ocean. This suggests weaker than normal surface wind speed over the Indian Ocean. The winter SSTa pattern associated with joint PC2 (Fig. 5f) shows that with cold SSTa over the Indonesia region, more rainfall would be distributed over India and Southern China.

Besides SSTa, we also checked the correlation of rainfall PCs with other long term climate indices (e.g., PDO and IOD), which is much less significant comparing to SSTa (below the significant level used in this study). Therefore, the

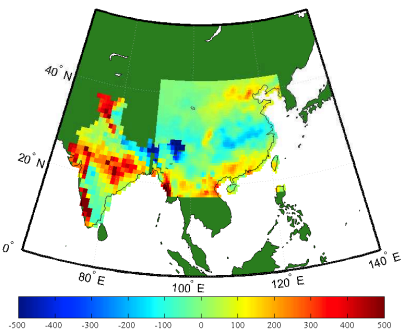

(a)

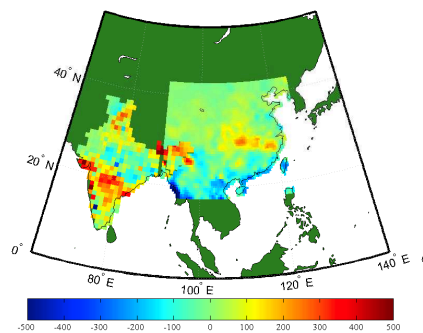

(c)

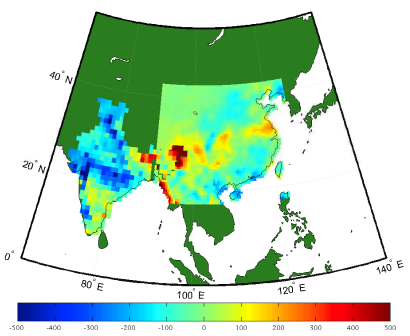

(b)

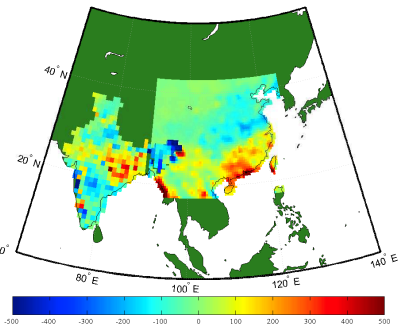

(d)
Fig. 6. Average rainfall anomaly in the monsoon months (JJAS) during five years with lowest or highest PCs values from Joint PCs. (a) Years with lowest PCs values from Joint PC1; (b) years with highest PCs values from Joint PC1; (c) years with lowest PCs values from Joint PC2; (d) years with highest PCs values from Joint PC2.

SSTa might probably serve as the most important influencing climate index for the annual variation of precipitation. As revealed by Chang (2000), Hu (2005) among many others, SSTa can in general affect rainfall through atmosphere circulation, especially moisture transportation processes. Our PCA results suggest that the physical mechanism affecting Chinese and Indian rainfall can be represented principally by the SSTa.

\subsection{Analysis of extreme years}

To gain further insight into the spatiotemporal correlation between Chinese and Indian monsoon rainfall, we analyzed the statistical data during the years when these leading modes strike extreme values. For each of the 4 joint PCs, we identified $10 \%$ (5 out of 53) of the years in which the joint PCs had the highest and the lowest values (Table 2). Then we made rainfall anomaly maps, moisture transport maps and SSTa maps for the average of $5 \mathrm{yr}$ with lowest PCs values and $5 \mathrm{yr}$ with highest PCs values. Looking at the average rainfall of years with highest PCs values from joint PC1, the Fig. 6a is consistent with the result from the Fig. 3a. The average rainfall of the five years with lowest PCs values from joint PC1 shows that Middle China and Southern India are dry, and the locations with negative correlation with $\mathrm{PC} 1$ are wet. The pattern is almost the opposite in the years with highest PCs values.

The Sea Surface Temperature pattern in the previous winter months (DJF) during the extreme years of joint PC1 
Table 2. Five years with lowest joint PCs values and those with highest values. Years labeled by stars are El Nino years, and ones labeled by daggers are La Nina years.

\begin{tabular}{|c|c|c|c|c|c|c|c|c|c|c|}
\hline \multirow[b]{2}{*}{ Joint PC1 } & \multicolumn{5}{|c|}{ Lowest } & \multicolumn{5}{|c|}{ Highest } \\
\hline & 1959 & 1961 & $1994 *$ & 1956 & $1978^{*}$ & $1965^{\dagger}$ & $1987^{*}$ & $1974^{\dagger}$ & $1991^{*}$ & $1999^{\dagger}$ \\
\hline Joint PC2 & $1983^{*}$ & $1998^{*}$ & $1988^{\dagger}$ & $1989^{\dagger}$ & $1964 *$ & $1994 *$ & $2001^{*}$ & $1997^{*}$ & 1952 & 1961 \\
\hline
\end{tabular}

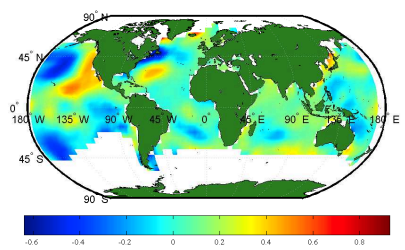

(a)

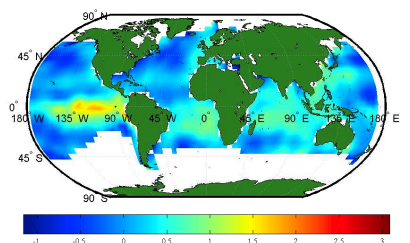

(c)

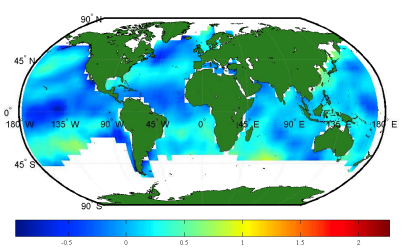

(b)

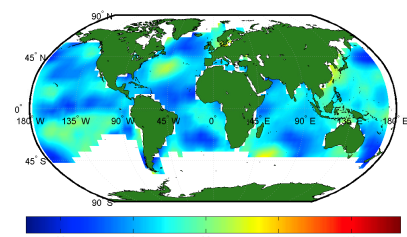

(d)
Fig. 7. Average SSTa in the previous winter months (DJF) during five years with lowest or highest PCs values from Joint PCs. (a) Years with lowest PCs values from Joint PC1; (b) years with highest PCs values from Joint PC1; (c) years with lowest PCs values from Joint PC2; (d) years with highest PCs values from Joint PC2.

indicates a weak relationship between joint PC1 and ENSO, as shown in Fig. 7a and b. During the lowest value years, the temperature in the ENSO region is slightly higher, but not high enough to present an El Nino phenomenon. The years with lowest PCs values from PC1 are wetter years for most regions in India. The Sea Surface Temperature pattern in DJF in years with lowest PCs values and years with highest PCs values from joint PC2 indicates a much clearer relationship between joint PC2 and ENSO, as shown in Fig. 7c and d. During the years with lowest PCs values, the temperature in the ENSO region is obviously higher. The years with lowest PCs values from PC2 are wetter years for lower Yangtze River basin in China and Southern India, and are drier years for Middle India.

Moreover, we studied five years average moisture transport during the years with lowest and highest PCs values determined from joint PC1 and PC2, which are shown in Fig. 8. As we can see from the figures, for the joint PC1, the average moisture transport during the years with lowest values in Western India is stronger and brings more precipitation into Middle India. On the other hand, the moisture transport during years with highest values is weaker and bring more

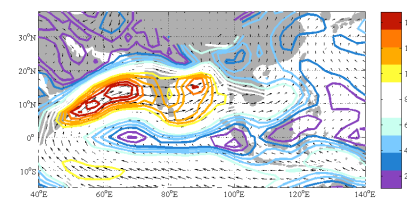

(a)

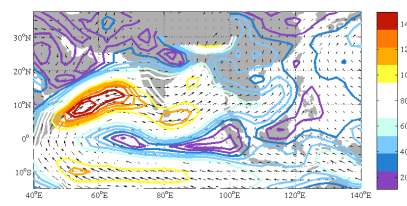

(c)

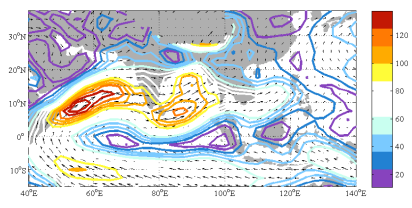

(b)

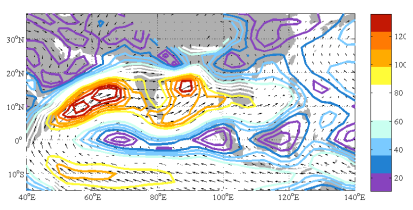

(d)
Fig. 8. Average moisture transport at $700 \mathrm{mb}-1000 \mathrm{mb}$ in the monsoon months (JJAS) during five years with lowest or highest PCs values from Joint PCs. (a) Years with lowest PCs values from Joint PC1; (b) years with highest PCs values from Joint PC1; (c) years with lowest PCs values from Joint PC2; (d) years with highest PCs values from Joint PC2.

precipitation into Southeastern and Northeastern India. For the joint PC2, the moisture from Indian Ocean is comparative during the years with lowest value compared to the years with highest values, while the moisture from Pacific Ocean during the years with highest values is a little stronger than the years with lowest values. This could serve as one reason that Southeastern China is wetter during the years with highest PC2 values than those with lowest PC2 values (Fig. 6).

These results from moisture transport coincide with the previous results discussed in Sect. 3.2. Joint PC1 is correlated with IMI, so that the variation of moisture fluxes from Indian Ocean plays an important role in monsoon precipitation during the peak years of joint PC1. Joint PC2 is correlated with WNPMI, so that the variation of moisture fluxes from West-North Pacific Ocean plays an important role in monsoon precipitation during the peak years of joint PC2.

Using joint PCA two trends in rainfall data in India and China are revealed as distinct moisture transport processes coming from Indian Ocean and North Pacific Ocean respectively. This result provides new insight into the physical mechanism behind the rainfall processes in India, China and surrounding regions. 


\section{Summary and conclusion}

Quite a few studies indicate that Chinese monsoon and Indian monsoon are correlated in some way. To explore the common structures of the two monsoons and the underlying physical mechanism at the annual scale, the yearly precipitation time series data from Indian and Chinese areas with the recording length of over $50 \mathrm{yr}$ were collected and analyzed by Principal Component Analysis method and Correlation Analysis method. After a traditional treatment of monsoon data (i.e., PCA of Indian monsoon and Chinese monsoon separately), a joint PCA were performed on the PCs of Indian monsoon and Chinese monsoon obtained from the previous PCA manipulation. Also, the correlation of monsoon rainfall and the PCs with SSTa and other large scale climate indices were explored and the extreme years were particularly selected for detail analysis.

Our results indicate the intertwined correlation between and within Indian monsoon and Chinese monsoon. For example, joint PCA clearly shows that the joint PC1 has high positive correlation with Middle China and Southern India and has high negative correlation with Northeastern China, part of Southern China, Northern India and Middle India. The results also show that Northern China garners less rainfall when whole Indian rainfall is below normal, while MeiYu over the Yangtze River Valley along about $30 \mathrm{~N}$ gets more rainfall. The possible reason might be the weaker than normal monsoon induced by warmer tropical SST and thus the smaller land-sea temperature difference. Under this circulation situation, Mei-yu advances northward slower and stays over Yangtze River valley for a longer time, which produces more rainfall there but less rainfall over Northern China. These characteristics and many other common features between Indian monsoon and Chinese monsoon suggest that both monsoons belong to a larger monsoon structure which should be studied as a whole. Compared to traditional utilization of PCA method separately on the rainfall data in the two monsoon regions, the joint PCA can give clearer patterns of Indian and Chinese monsoon rainfall.

Furthermore, the analysis reveals the teleconnections between monsoon rainfall and monsoon indices (IMI/WNPMI), SSTa and other large scale climate indices. For example, our results suggest two moisture sources for Indian monsoon and Chinese monsoon, i.e., the Indian Ocean and West Pacific Ocean, each of which dominates monsoon rainfall in different areas indicated by the joint PCs. The results also show that generally the SSTa in the previous winter season can be linked to the following summer monsoon rainfall, and specifically with cold SSTa over the Indonesia region during winter season more monsoon rainfall would be distributed over India and Southern China in summer season. This provides predictability for Indian and Chinese monsoon rainfall through joint PC1 and PC2, which will be presented in more detail in a following paper (Zhou et al., 2011).
Acknowledgements. We thank World Climate Research Programme for providing all the data used in this study. The work was funded in part by the National Science Foundation of China (NSFC 50823005, 51179084), China Scholarship Council, and Water Center of Columbia University. The financial support is gratefully acknowledged.

Edited by: M. Sivapalan

\section{References}

Abrol, Y. P. and Gadgil, S. (Eds.): Rice- in a Variable Climate, APC Publications, Pvt Ltd, New Delhi, 243 pp., 1999.

Chang, C. P., Zhang, Y. S., and Li, T.: Interannual and interdecadal variations of the East Asian summer monsoon and tropical Pacific SSTs, Part I: roles of the subtropical ridge, J. Climate, 13(24), 4310-4325, 2000.

Chan, J. C. L. and Zhou, W.: PDO, ENSO and the early summer monsoon rainfall over south China, Geophys. Res. Lett., 32, L08810, doi:10.1029/2004GL022015, 2005.

Kripalani, R. H. and Kulkarni, A.: Monsoon rainfall variations and teleconnections over South and East Asia, Int. J. Climatol., 21(5), 603-616, 2001.

Kripalani, R. H. and Singh, S. V.: Large scale aspects of IndiaChina summer monsoon rainfall, Adv. Atmos. Sci., 10(1), 71-84, 1993.

Hu, Z., Wu, R., James, L., and Yang, S.: Connection of summer rainfall variations in South and East Asia: role of El Ninosouthern oscillation, Int. J. Climatol., 25(9), 1279-1289, 2005.

Huang, R. and Sun, F.: Impacts of the thermal state and the convective activities in the tropical western warm pool on the summer climate anomalies in East Asia, Chinese J. Atmosph. Sci., 18(2), 46, 1994.

Parthasarathy, B., Munot, A. A., and Kothawale, D. R.: Regression model for estimation of Indian food grain production from Indian summer rainfall, Agr. Forest Meteorol., 42, 167-182, 1988.

Wang, B., Wu, R., and Lau, K. M.: Interannual variability of Asian summer monsoon: Contrast between the Indian and Western North Pacific-East Asian monsoons, J. Climate, 14, 4073-4090, 2001.

Webster, P. J., Magana, V. O., Palmer, T. N., Shukla, J., Tomas, R. T., Yanai, M., and Yasunari, T.: Monsoons: Processes, predictability and the prospects of prediction, J. Geophys. Res., 103(C7), 14451-14510, 1998.

Yang, F. L. and Lau, K. M.: Trend and variability of China precipitation in spring and summer: linkage to sea-surface temperatures, Int. J. Climatol., 24(13), 1625-1644, 2004.

Zhang, Q., Xu, C. Y., Jiang, T., and Wu, Y. J.: Possible influence of ENSO on annual maximum streamflow of the Yangtze River, China, J. Hydrol., 333(2-4), 265-274, 2007.

Zhou, M., Tian, F. Q., and Hu, H. P.: Long-term prediction of Yichang streamflow based on Joint Principal Component Analysis, Journal of Hydroelectric Engineering, accepted, 2011. 